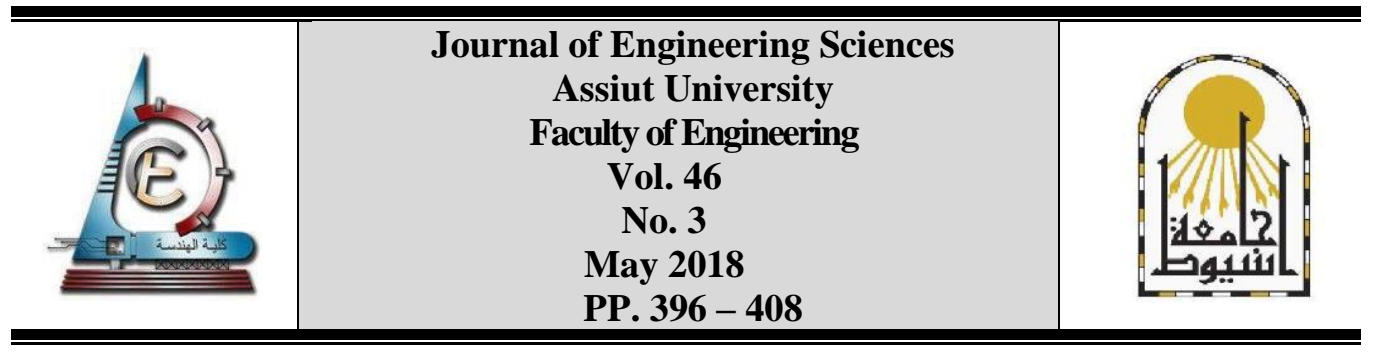

\title{
PROMOTING MOBILITY TO IMPROVE QUALITY OF LIFE IN NEW CITIES
}

\author{
Reham Ibrahim Momtaz ${ }^{1, *}$, Rasha M. Shaban ${ }^{2}$ \\ Modern Academy for Engineering and Technology
}

Received 15 March 2018; Accepted 1 April 2018

\begin{abstract}
Mobility is one of the main factors to promote the quality of life for the citizens; a low level of mobility is generally leading to a low quality of life, as it may become a barrier to satisfaction of basic needs and participation in social life. The paper focuses on identifying the urban quality of life, the relevance of its mobility urban quality of life concept and studying the indicators of mobility. Moreover, the paper investigates Al-Rehab City as one of new communities in Cairo' to identify variables of street connectivity and determine the relationship between land use and mobility by applying Space Syntax.

The paper aims to prove the impact of multi modal, walkable and effective transport system in improving the quality of life and encouraging citizens to move to new cities, which leads to achieve the Expected population capacity in Egyptian new cities.

Finally, the paper is concluding with concrete results in the measurement of quality of life features in Al-Rehab city that concerning the mobility dimension, accessibility, pedestrian catchment area and connectivity. Also, using space syntax techniques can verify these features which will contribute to the establishment of sustainable residential areas.
\end{abstract}

Keywords: Quality of Life, Mobility, Connectivity, Accessibility, Al-Rehab City, Space Syntax.

\section{Introduction}

The mobility within cities is one of the main dimensions of the quality of urban life, which is linked to accessibility, traffic and transportation. Many of the new cities in Egypt face several problems, such as the length of travel distance of vehicles, the inadequate level of services, poor distribution of land uses, and other urban problems which reflects the inability of these cities to achieve a target population in the goal year, Moreover, it negatively affects the quality of life of citizens.

\section{Quality of life}

There are many studies that focus on the notion of quality of life, but without any consensus has been reached on how to define. Furthermore, the notion of quality of life is

\footnotetext{
* Corresponding author.

E- mail address: reham.momtaz@yahoo.com
} 
utilized interchangeably with other notions such as human well-being, happiness, life satisfaction and the livability [1].

Quality of life is defined as the citizen's satisfaction in life through promoting their healthy life, social relations, etc., rather than their financial position. Moreover, the individual satisfaction is related to several conditions for instance cultural and intellectual conditions under which he lives [2]. The notion of quality of life reflects how well individual needs are fulfilled in various fields of life [3], which affect psychical and social aspects for citizens [4].

\subsection{Urban quality of life}

The quality of urban life is a complex idea, which encompasses all the dynamics and interrelated relationships that exist between the social, environmental, economic, political, dimensions of this concept. "It was necessary to understand and determine the requirements of people in the same socioeconomic status and social standards, since the citizens seek different needs. The city and even the neighborhood respond differently to fulfill their needs [5].

\subsection{Urban quality of life dimensions}

Urban quality of life is a multi-dimensional concept, which is represented by an integrated relationship between various dimensions such as environmental, physical, mobility, social, psychological, economic and political urban quality of life. These dimensions are integrated with each other as reflected in [Figure- 1] [6] whereas urban quality of life relationships differ and are determined according to places and societies. The planners focus on the improvement of urban quality of life in particular places. So, the stakeholders and planners insist on improving the quality of public spaces, land use patterns, mobility, ease of access for all to basic needs, services and public amenities, as well as, social aspects [7].

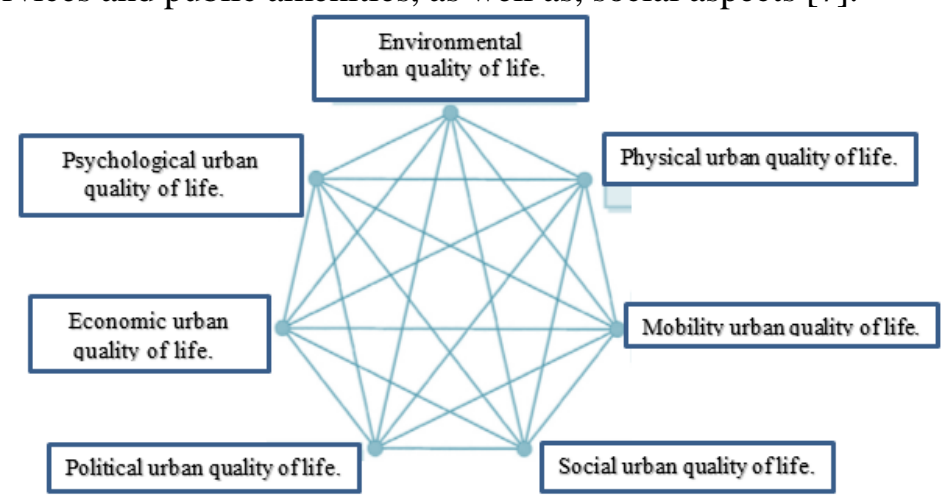

Fig. 1. Urban Quality of Life Dimensions [1].

\section{Livable city is a mobile city}

Mobility contributes in promoting the quality of life. It is the precondition for economic growth, trade and creativity, as well as for personal wellbeing. Citizens who can easily move around in the city can enjoy more of life's opportunities. Mobility creates access to opportunities for advancement, individuals and for the community as a whole.

The livable city needs sustainable mobility systems to make it healthier, safer, climatefriendly and flourishing. Greater mobility does not certainly mean more traffic but in fact, it means precisely the opposite when long term planning creates a city of short distances. 


\subsection{Mobility urban quality of life}

Based on studies, there is a relation between people's well-being and their mobility [8; 9; 10].The well-being term is synonymous with "quality of life" which measures subjectivity and shows an individual's life from his own point of view [11]. Lack of mobility reduces the quality of life since they are directly proportional, so it may become a barrier to satisfaction of basic needs and participation in social life [12]. Having access to transportation, particularly public transportation, is crucial for ensuring access to employment and education).

Agenda 21 addresses profound recommendations for efficient and environmentally sound urban transport systems, as following [2]:

1. Integrate land-use planning and transport to promote a development pattern that reduces demand for transport and supports other environmental means.

2. Adoption of urban transport programs to support public transport throughout the country

3. Providing safe roads and corridors in urban areas

4. Attention to traffic management and periodic maintenance of roads.

5 - Reassess the different modes of transport, in order to reduce the use of energy and improve the environmental aspects.

Mobility urban quality of life has multi-dimensional indicators such as accessibility, walk ability, cycle ability, traffic load and public transportation. The paper only focuses on accessibility, which included pedestrian catchment area and connectivity.

\subsection{Accessibility}

Accessibility is often utilized in human geography to evaluate a spatial distribution of facilities and functions and investigate the easy accessibility to places by pedestrians or by a convenient mode of transport [13]

It denotes the ease with which any land-use activity can be reached from a location, using a particular transport system [13]. Accessibility is also considered as the opportunities available to an individual to take part in a particular activity or set of activities. Therefore, an exemplary measurement of accessibility consists of two parts [14]:

A. The impedance or difficulty of travel is represented by transportation elements. Travel distance, time, or costs (usually walking distance is measured by kilometer while the distance covered by vehicles is measured by travel time) are used to measure these elements.

B. An activity component is the opportunities for individuals and communities to participate in different activities, which make people more sociable and more aware about the economic and health life opportunities.

\section{- Pedestrian catchment area}

The public health studies reveal the relation between neighborhood design and mobility. Hence the central concept is utilized in neighborhood design to meet pedestrians' needs and make mobility more convenient when many destinations are clustered close together [Figure -2] [15]. 


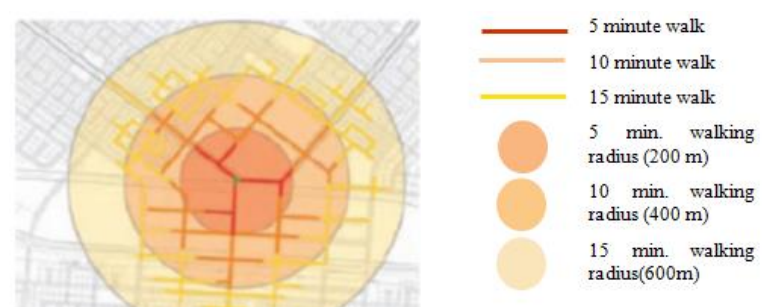

Fig. 2. Pedestrian catchment area [16]

According to Newman and Kenworthy a pedestrian catchment area or "Ped shed", based on a 10 minute walk, creates an area of approximately 2.2-5.5 km2 (walking distance is about $800 \mathrm{~m}-1300 \mathrm{~m})[17]$.

The UK government states a ten minute walk is a comfortable enough time to reach services and facilities (based on younger adults, walking distance is about $800 \mathrm{~m}$. [18]

The New Urbanism approach focus on creating suitable neighborhoods that encourage walking through achieving many considerations such as, most of the residents must be within a five-minute walk of the center (walking distance is about $400 \mathrm{~m}$ ), an elementary school is close enough which allows children to walk from their home and connected street networks are shaded by rows of trees. [19]

The Urban Village approach claims, "The convenient walking distance usually defines a 10 minute walk from one side of the urban area to the other" (up to $900 \mathrm{~m}$ across) [20].

\section{- Connectivity}

Interconnected street networks are at the core of new urbanism, which adds to the value of communities and neighborhoods through building more sustainable communities, supporting public health by encouraging physical activity and reducing the negative effects of motor vehicle emissions [21].

Well-planned connectivity can help distribute traffic, improve routing, reduce walking distances and provide guidance opportunities for emergency and delivery vehicles. Thus, all of these effects can play a positive role in reducing congestion in the street network [22].

Maximum block length is a way to evaluate connectivity in cities because network patterns with shorter blocks (instead of long dead end streets or cul-de-sacs) ease access from one place to another within the community and provide alternative routes, thus reducing traffic congestion as well as increasing options for pedestrian activity. Connectivity relates not only to the number of intersections along segment of the street, but also to how to connect an entire area by the street system [23].

\section{Integration mobility quality of life aspects in new cities}

Space syntax is a set of analytical, quantitative and descriptive tools for analyzing the spatial formations in different forms which aims to understand the different variables and its approach, The explanation of the basic indicators of Space Syntax methodology [Table -1-] [24]. 
Table 1.

The Explanation of the Basic Indicators of Space Syntax

\begin{tabular}{|c|c|}
\hline Indicators & Description \\
\hline $\begin{array}{l}\text { Connectivity value } C i \\
C_{i}=k\end{array}$ & $\begin{array}{l}\text { This is called a local measure which is utilized to define the value } \\
\text { of a space or axial lines that connect to other lines in the system } \\
\text { " } k \text { refers to the total number of spatial units directly connected to } \\
\text { the given spatial unit and i reflects its capability to be connected to } \\
\text { other spatial units in the topological network " }\end{array}$ \\
\hline Mean Depth & $\begin{array}{l}\text { The mean number of spaces away from all other spaces in the } \\
\text { system from selected space. }\end{array}$ \\
\hline $\begin{array}{l}\text { Depth value D } \\
\qquad \bar{D}=\frac{\sum_{\mathrm{d} 1}^{s} \mathrm{~d} \times N_{\mathrm{d}}}{n-1}\end{array}$ & $\begin{array}{l}\text { Reflect the shortest step-distance measured between a specific } \\
\text { spatial unit and an other } \\
\text { "n is the number of node to be studied." }\end{array}$ \\
\hline $\begin{array}{l}\text { Integration Value } \mathrm{RA}_{\mathrm{i}} / \mathrm{RRA}_{\mathrm{i}} \\
\qquad R A_{i}=\frac{2(\bar{D}-1)}{n-2} \\
R R A_{i}=\frac{R A_{i}}{D_{n}}\end{array}$ & $\begin{array}{l}\text { This is a static global measure, which measures the average } \\
\text { distance between the axis and all other axes of the system. } \\
\mathrm{RA}_{\mathrm{i}} / \mathrm{RR}_{\mathrm{i}}>1 \text {, indicates to higher degree of centralization, when } 0.4 \\
<\mathrm{RA}_{\mathrm{i}} / \mathrm{RR}_{\mathrm{i}}<0.6 \text { indicates to relatively disperse. }\end{array}$ \\
\hline
\end{tabular}

\subsection{Case study of al rehab city}

One of the first gated communities in New Cairo was Al Rehab city. It is located in the northern part of New Cairo on the Cairo-Suez Road, approximately $27 \mathrm{~km}$ east of Cairo as shown in [Figure-3].

Al Rehab aimed to create a self-sustaining city by offering a variety of services and amenities in addition to the residential areas. The construction of 'Al Rehab I' was divided into six districts and 3 districts in 'Al Rehab II' as shown in [Table-2]. These ten districts containing villa areas as well as apartment building areas were arranged around the socalled green heart of Al Rehab. The services and amenities are located along a ring road running through all the districts as shown in [Figure-4] [24].

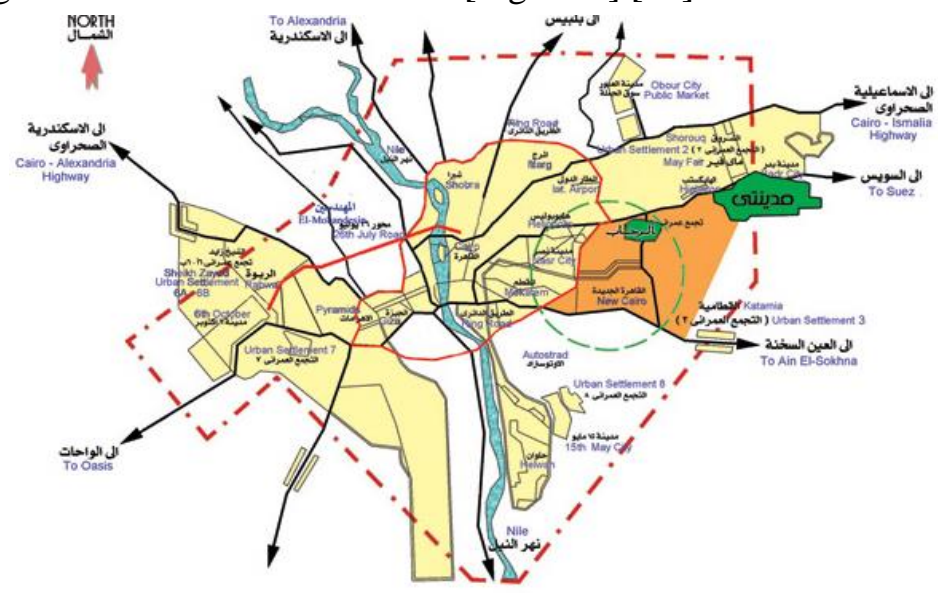

Fig. 3. Al-Rehab location [23] 


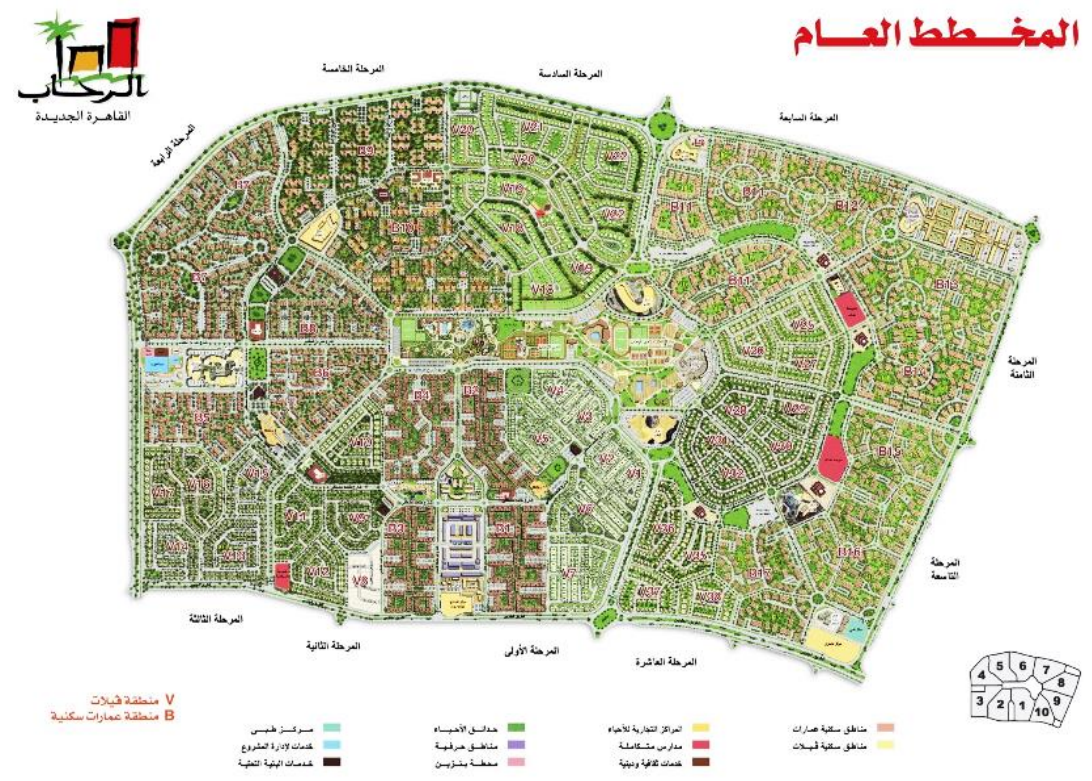

Fig. 4. Al-Rehab masterplan [24]

Table 2.

Describe Al-Rehab city and expected population [24; 25]

\begin{tabular}{|l|l|}
\hline \multicolumn{2}{|l|}{ Location: New Cairo Al Rehab I, Al Rehab II } \\
\hline City generation & 1996 third generation \\
\hline City type & dependable \\
\hline Goal year & 2016 \\
\hline Total land size (m2) & $9.900 .000 \mathrm{~m}^{2}$ \\
\hline Expected population & 200.000 \\
\hline Al Rehab I & \\
\hline (district 1-6) Area & $6.140 .000 \mathrm{~m}^{2}$ \\
\hline Expected population Al Rehab I & 120.000 \\
\hline Al Rehab I Construction & $1996-2011$ planned, except district 6 \\
\hline Al Rehab II & \\
\hline (district 7-10) Area & $3.760 .000 \mathrm{~m}^{2}$ \\
\hline Expected population Al Rehab II & 80.000 \\
\hline Al Rehab II Construction & $2006-2017$ Projected \\
\hline \% of sold residential (Rehab II) & $92.7 \%$ \\
\hline
\end{tabular}

The distribution of services of all types services commensurate with the target populations, such as churches, mosques, hospitals and recreational areas which has been distributed according to the construction phases and also taken into account the connectivity, access and distances between residential areas and the various services which provides many aspects of quality of life[25].

\subsection{Methodology}

The paper methodology depends on Space Syntax Analysis to measure connectivity, integration, mean depth and total depth of mobility quality of life in Al- Rehab city [Figure-5]. 


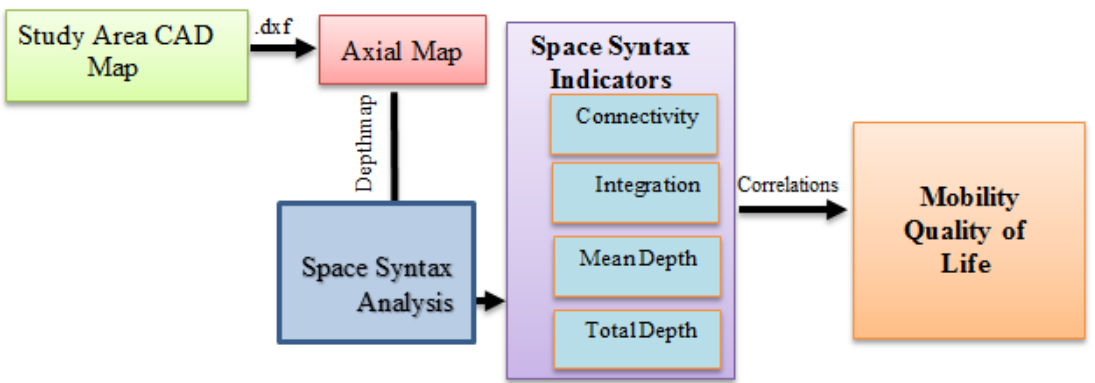

Fig. 5. study Methodology

The axial map of AL-Rehab was drawn by AutoCAD program and exported as dxf. cad file to UCL Depthmap software. The processing of axial lines helped getting connectivity and integration values with different radius to analyze the mobility characters of AL-Rehab city. The axial lines are represented from blue to red, red means the highest value of the parameter while light blue means the lowest value in [Figure-6]

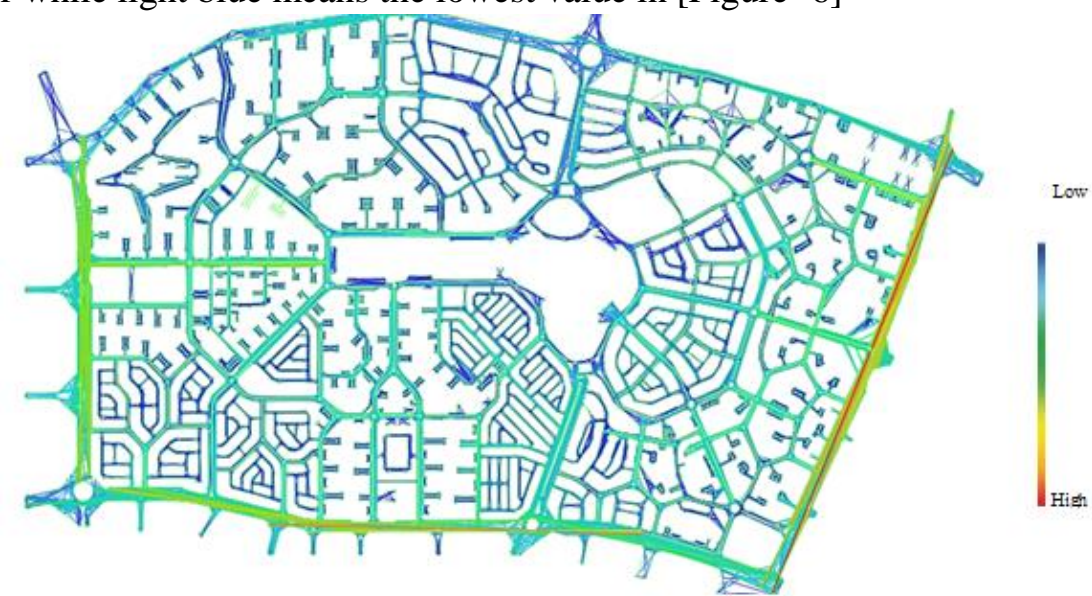

Fig. 6. Axial map of Al-Rehab

\subsection{Results analysis}

Using axial map as a syntactic map, which depicts number of axial lines covering all entire spaces of layout and connections, is to get various measurements including integration and accessibility of minor and local roads that means focusing on conduct a segment analysis of the streets to analyze properties of the geometry of Al Rehab city by using of the following attributes connectivity, integration, Mean depth and total depth.

Table. 3.

Depthmap attribute of Al-Rehab

\begin{tabular}{|c|c|c|c|}
\hline Attribute & Minimum & Average & Maximum \\
\hline Connectivity & 1.000 & 9.286 & 52.000 \\
\hline Integration & 0.758349 & 1.238111 & 1.961945 \\
\hline Mean Depth & 5.464272 & 8.247958 & 12.54963 \\
\hline
\end{tabular}




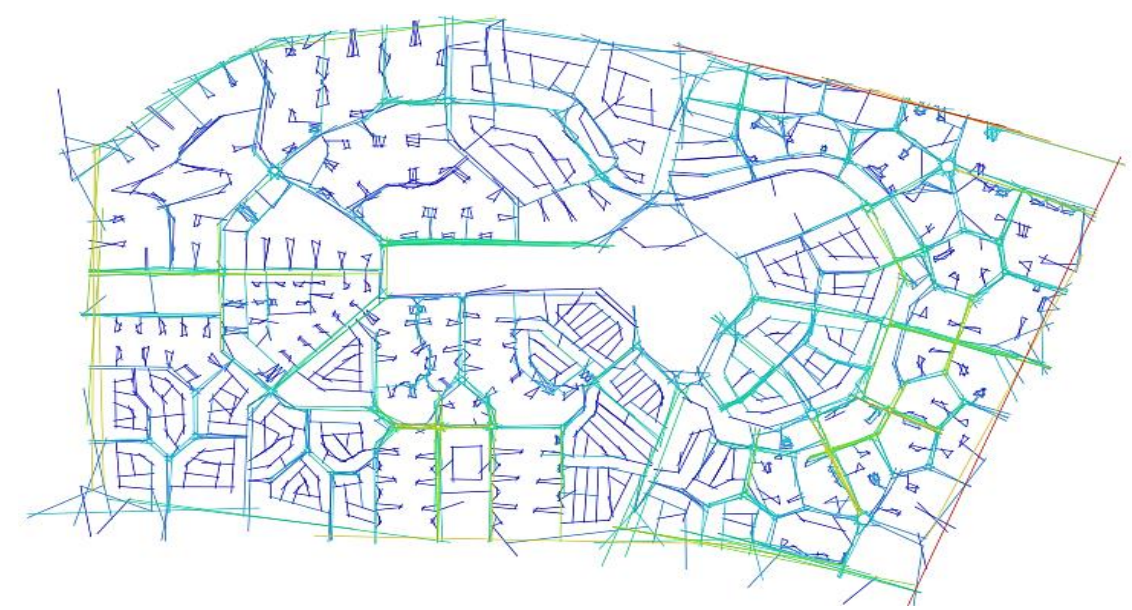

Fig. 7. Spatial Connectivity analysis of Al-Rehab roads

Connectivity analysis shows how often a street is connected to another street. The analysis shows a gap [Figure-7], some are concentrated in high values, the very low values of connectivity. The lowest values are as a result of housing types in the city. The highest values correspond to the axis "Youssef Elsebai", which offers a large number of resolutions on the pedestrian routes or movement of cars more likely to reach other houses, parks, and services.

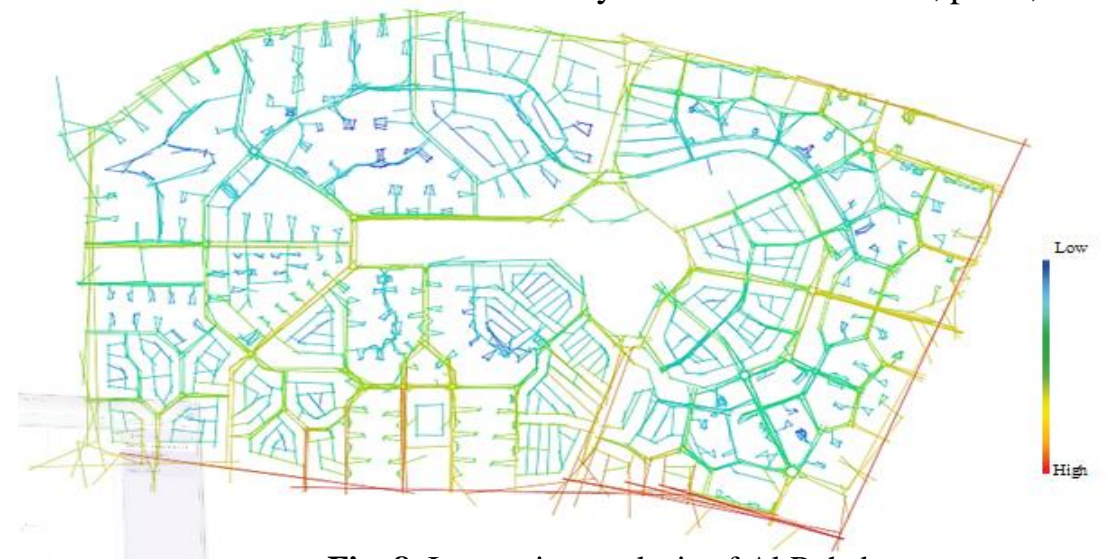

Fig. 8. Integration analysis of Al Rehab

Integration analysis describes how to get one segment from all other segments, and how many turn to reach the place by apply it to the Al Rehab City [Figure-8].

It shows the main exit of the city have high integration values, the less integrated axes with integration value $(\mathrm{Rn})$, which is 0.758 (blue color) indicates to residential area individually attributes away from the center and incomplete inner urban lack of center or limit urban services, which mean the most integrated axes with integration value $(\mathrm{Rn})$, which is 1.961 (red color) associated with commercial land use and the streets connected to recreation and green land use, these high values of integration make that in these axes the natural movements in city.

However, the most segregated or less integrated axes are located on the west part of the city where residential neighborhood has high privacy and lower integration. These values mean that natural pedestrian movement in a local scale. In addition, some exterior axes have higher integration. 


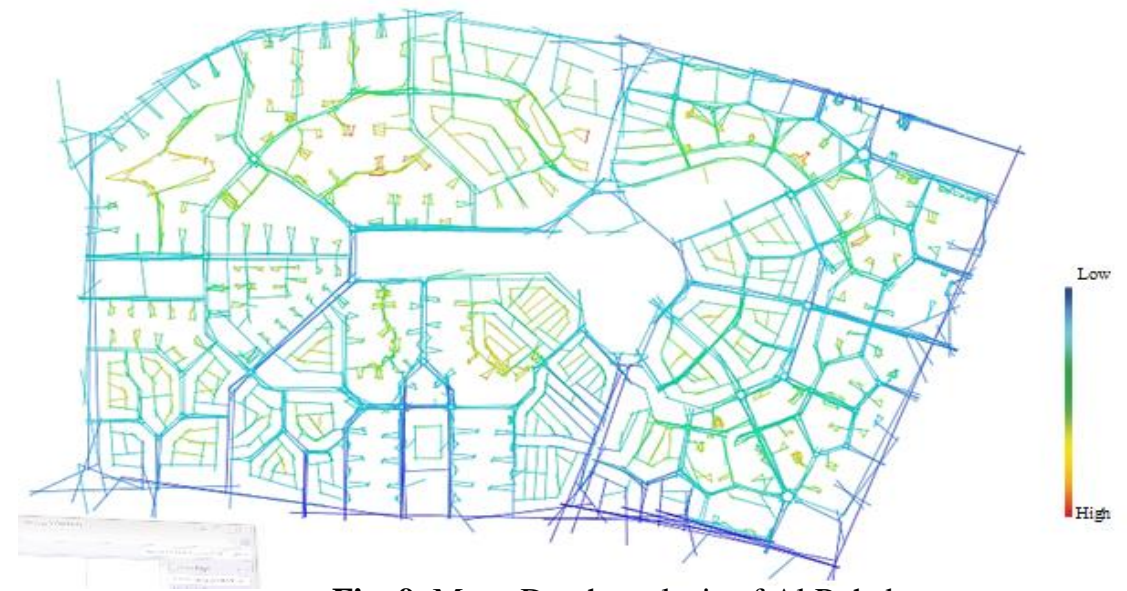

Fig. 9. Mean Depth analysis of Al Rehab

Mean depth refers to the number of visual space steps to a certain space in the urban fabric, the results showing the deep areas within the urban fabric of the city is less than the space depth in areas overlooking the main streets as a result of the steps 12549 visual few. Which mean that pedestrians in the city in 12549 were needed deep steps or roll to cover the entire city [Figure-9].

In Total depth graph analysis generated for the Al Rehab Districts, the measures are applied with different radius: R400 with minimum depth (162.8248), and maximum (102609.00) as a shortest distance, and for fewest turns distance R800 with maximum depth (686961.00), least angle change distance R1300 with maximum depth (2300839.00) [ Table-3].

Table.3.

Total depth radius distance

\begin{tabular}{|l|c|c|c|}
\hline Total Depth & R400 & R800 & R1300 \\
\hline Minimum & 162.83 & 162.83 & 162.83 \\
\hline Average & 41205.88 & 341216.73 & 1394951.2 \\
\hline Maximum & 102609.00 & 686961.00 & 2300839.00 \\
\hline
\end{tabular}

Based on the results [Table -3], the streets have traffic-friendly measures. This integrated system of different modules of travel within the neighborhood's road network, including pedestrian walkways, and transportation stops, makes difference compared to the traditional neighborhood form there are a large number of short paths are connected to both mosques and local streets in the neighborhood, more than the major arterial. That most of short angular paths are connected to main roads within the walking distances: $400 \mathrm{~m}$, which affects the accessibility of the building or open spaces aligned to them or located near them. 


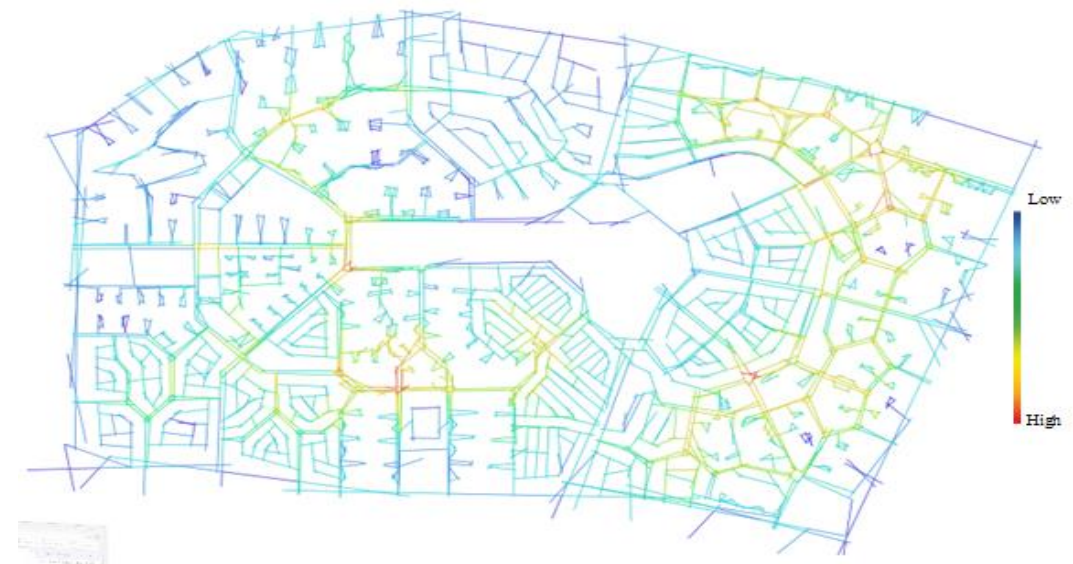

Fig. 10. Total Depth R400

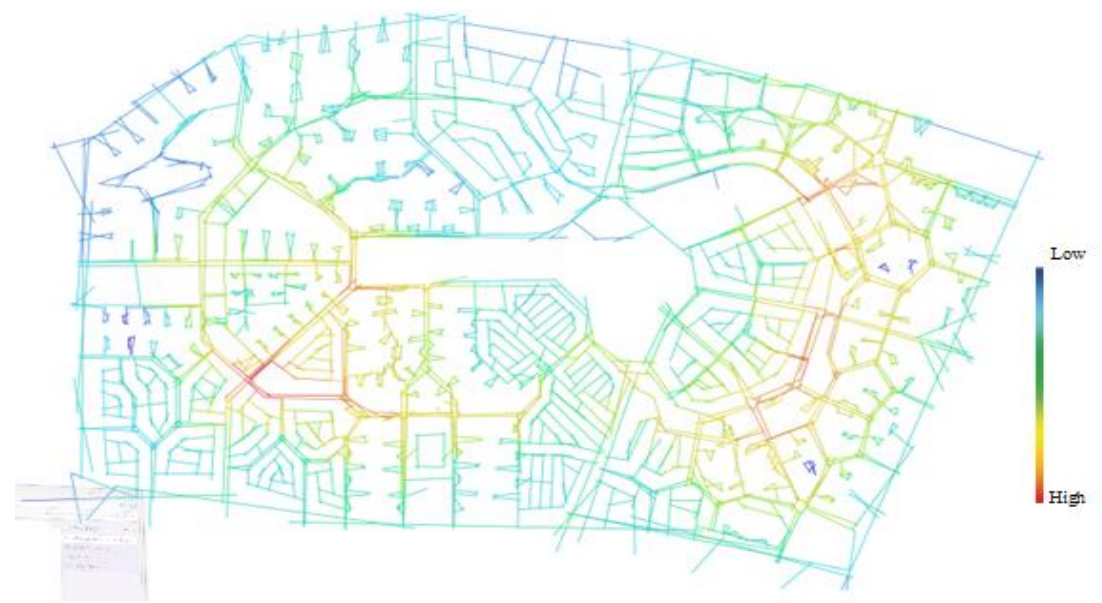

Fig. 11. Total Depth R800

The central distribution of services covers many houses because of the adoption of the small pattern of urbanization. This design achieves better total depth measures (686961.00). However, the District Urban design does not meet the services standard in some residential clusters in the upper left side of housing a total depth is under average (41205.88).

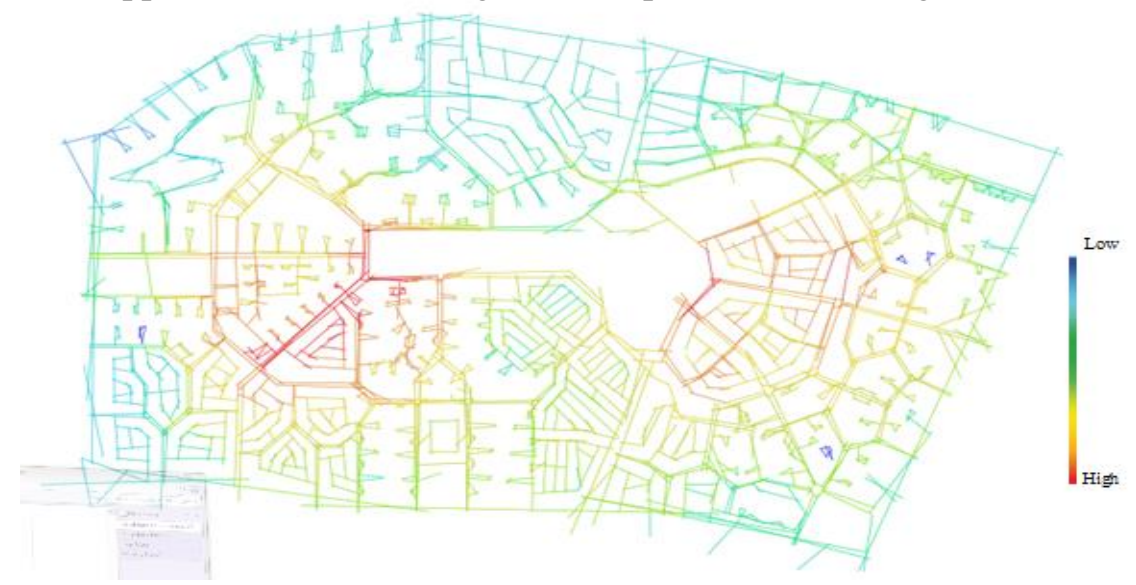

Fig. 12. Total Depth R1300 
Illustrated by [Figure-12], Street design with the catchment requirements, the location of center in an order that most of the community is within a fifteen-minute walking distance. The convenient walking distance allows pedestrians to choose the shortest path to the destination, which upgrade the livability of urban environments in Al-Rehab city by the promotion of walking, reduce the use of private cars in general, and minimize air pollution.

\section{Conclusions and Further Research}

The paper managed to understand how the mobility effects on improving quality of life in new cities through a profound theoretical and practical analysis, which is shown in two stages:

The first stage composes of theoretical review of quality of life, its indicators and mobility urban quality of life. The main aim of this stage is to determine multi-dimensional indicators of mobility.

The second stage, the paper depended on the space syntax techniques to evaluate mobility quality of life in Al Rehab city. Among the findings of this paper are the following:

Al-Rehab city has achieved good integration between the residential areas within the neighborhood, and services in each in the districts, and between the neighborhood and the city.

Accessibility to the road network in Al-Rehab city was quantified and analyzed through a series of an analysis variables using space syntax. Using segment analysis and total depth graphs were produced for different radius that correspond to walking distances to check city accessibility.

Based on results, AL-Rehab city has a good mobility to transport residents, as well as providing pedestrian network to adequately serve the requirements of community. the accessibility ranking system of urban space, the transport infrastructure, and connectivity of the network streets were strengthened the dominant position of Al-Rehab city.

The designers and planners must considerate places of services in new urban developments to respond for changing conditions. The community's quality of life depends upon accessibility and services provided to each land use, which could result in an increase of the possibilities of population to enjoy the benefits that city provide. Moreover, they must do regular evaluations be conducted when new development and redevelopment occur.

Mobility is not only important in fulfilling the essential needs of citizens, but also in promoting physical state, creating a sense of control and independence, helping people interact with nature and exercise cognitive skills. Hence, mobility, although linked to accessibility, is more than that to the citizens, especially when relating to quality of life. Furthermore, the mobility is a proven, effective indicator to assist communities in addressing their built environment to support better-connected, more sustainable places and enhance quality of life.

Obviously, Well-designed pedestrian network in new cities is a key component to create a livable community and improve environmental aspects like, reducing the urban heat island effect, noise reductions and providing air quality. Furthermore, it contributes physical and psychological benefits, which promote human health, wellbeing and satisfaction

Future study of this research is to integrate the questionnaire results of the accessibility and connectivity preference, depending on other factors in the quality of the mobility quality of life and socio-economic relations, to reach more efficient access to the standards and methods of the planners of the traditional methods. 


\section{REFERENCES}

[1] Sarah A., (2012). Neighborhood Urban Quality of Life: Guidelines for Urban Planning and Development of New Assessment Tool. A Thesis Submitted to the Faculty of Engineering, Cairo University (PHD).

[2] UN Conference on Environment and Development (UNCED) held in Rio de Janeiro, Brazil, in 1992

[3] Wunsch D. \& Risser R. (2002). Lebensqualität: Definitionen - Konzepte (Life quality definition and concepts). Referat am BDP-Kongress für Verkehrspsychologie, Regensburg

[4] SnoekF. J. (2000). Quality of life: A closer look at measuring patients' well-being. Diabetes Spectrum, Vol. 13(1),p24

[5] Sun Y.(2005). Development of Neighborhood Quality of Life Indicators, University of Saskatchewan, Canada.

[6] Hamam S., Ahmed Sh., Hend F.,Sarah A.(2013). Principles of urban quality of life for a neighborhood. Housing and Building National Research Center, HBRC Journal.

[7] McCrea R., Stimson R., Western J. (2005). Testing a moderated model of satisfaction with urban living using data for Brisbane,South East Queensland, Soc. Indic. Res. 72 , pp:121-152

[8]Kim, S., Ulfarsson, G. (2013). Transportation in an aging society: The linkage between Transportation and quality of life. Paper presented at the Annual Meeting of the Transportation Research Board, Washington DC.

[9] Kim, T., Choo, S., Shin, Y., You, S. (2013). Identifying differences of travel time budgets between the elderly and the non-elderly groups using PSL-structural equation models: A Case Study for Seoul metropolitan area. Paper presented at the Annual Meeting of the Transportation Research Board, Washington DC.

[10] Duarte A., Garcia C., Giannarakis G., Limão S., Polydoropoulou A., Litina N. (2009).New approaches in transportation planning: Happiness and Transport economics. NETNOMICS: Economics Research and Electronic Networking, 11(1), 5-33.

[11] Davies D., Stock S., Holloway S., Wehmeyer M. (2010). Evaluating a GPS-based transportation device to support independent bus travel by people with intellectual disability. Intellectual and Developmental Disabilities, 48(6), 454-464.

[12] Sammer G., Uhlmann T., Unbehaun W., Millonig A., Mandl B., Dangschat J., Mayr R. (2012). Identification of Mobility Impaired Persons and Analysis of their Travel Behavior as well as their Needs. Paper presented at the Annual Meeting of the Transportation Research Board, Washington DC.

[13] Garling V., Steg L. (2007). Threats from Car Traffic to the Quality of Urban Life, first ed., Elsevier, Amsterdam.

[14] Handy S.(2005).Planning in Accessability In Theary and In Practice. Elsevier,

http://www.des.ucdavis.edu/faculty/handy/Access_chapter.pdf

[15] Douglas F. (2008).Sustainable Urbanism, ed. John Wiley \& Sons, Hoboken, NJ.

[16] Abu Dhabi Urban Street Design Manual (2013), Abu Dhabi Urban Planning council.

[17] Newman, P., Kenworthy, J. R. 1989a. Cities and Automobile Dependence: An International Sourcebook. Aldershot, UK: Gower Technical

[18] Department of Transport, Local Government and the Regions (DTLR), 2001.

[19] B. Franklin, M. Tait, Constructing an image: the urban village concept in the UK, Plan. Theory 1 (2002) 250-272.

[20] Samaneh R.(2015). Using principles of urban villages as a solution to improve life quality of citizens. Cumhuriyet University, Faculty of Science, Science Journal (CSJ), Vol. 36, No: 3

[21] North Carolina Complete Streets Planning and Design Guidelines,(2012) North Carolina Department of Transportation Complete Streets Policy from: http://www.pedbikeinfo.org/pdf/PlanDesign_SamplePlans_CS_NCDOT2012.pdf

[22] Gebel K, King L, Bauman A, Vita P, Rigby A, and Capon A., (2005) Creating Healthy Environments: A Review of Links between the physical environment, physical activity and obesity, NSW Health Department and NSW Centre for Overweight and Obesity, Sydney.

[23] Handy, S. (2003). Planning for Street Connectivity: Getting from Here to There, Planning Advisory Service, Report No. 515. Chicago: American Planning Association, May.

[24] Hillier, B., Hanson J., 1997, The Reasoning Art: Or, the Need for an Analytic Theory of Architecture, M.D. Major, L. Amorim, F. Dufaux (Eds.), Proceedings, 1st International Space Syntax Symposium, University College London, v. I.

[25] TMG (Talaat Moustafa Group) (2015) Annual Report 2015. [Online], http://talaatmoustafa.com/Portals/0/TMG\%20Presentation-Sep\%202015.pdf Accessed 2.03.2018. 


\section{تعزيز القدرة على الانتقال كمدخل لتحسين جودة الحياة فى المدن الجديدة}

\section{الملخص العربى:}

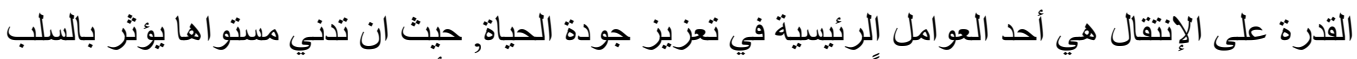

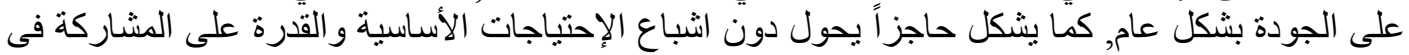

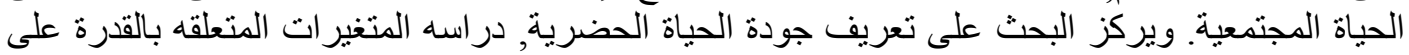

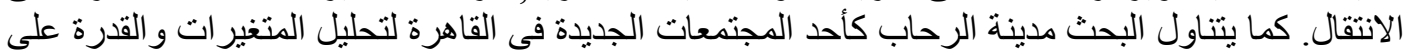

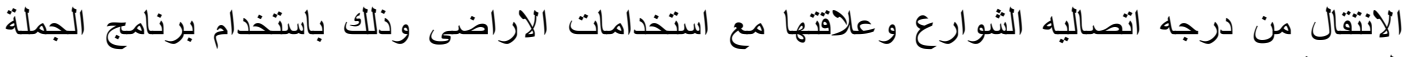

الفر اغية (Space Syntax).

يهدف البحث إلى إثبات تأثثير نظام النقل متعدد المستويات وفعاليته في تحسين جودة الحياة وتشجيع التهي

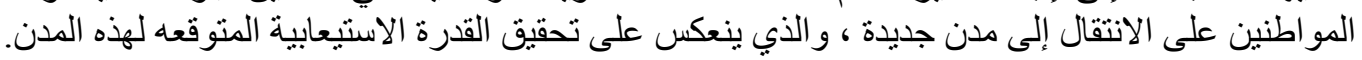

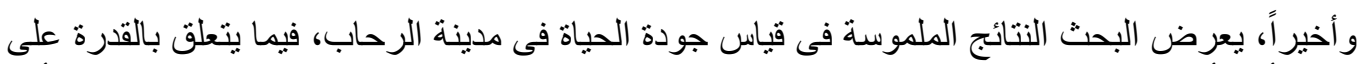

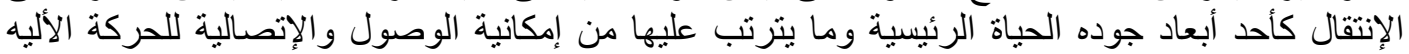

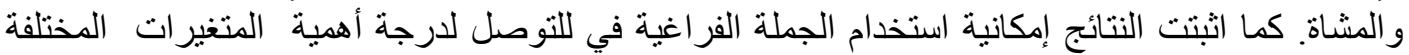
التى تساهم تحقيق استدامه المناطق السكنية.

الكلمات المفتاحية: جودة الحياة، الانتقالية، الاتصالية، امكانية الوصول، مدينه الرحاب، تقنيات الجملة الفر اغية. 